\title{
Real-Time High-Rate GNSS Displacements: Performance Demonstration during the 2019 Ridgecrest, California, Earthquakes
}

Diego Melgar ${ }^{\star 1}$, Timothy I. Melbourne², Brendan W. Crowell ${ }^{3}$, Jianghui Geng ${ }^{4}$, Walter Szeliga², Craig Scrivner², Marcelo Santillan², and Dara E. Goldberg ${ }^{1}$

\begin{abstract}
Traditional real-time (RT) seismology has relied on inertial sensors to characterize ground motions and earthquake sources, particularly for hazards applications such as warning systems. In the past decade, a revolution in high-rate, RT Global Navigation Satellite Systems (GNSS) displacement has provided a new source of data to augment traditional measurement devices. The Ridgecrest, California, earthquake sequence in 2019 provided one of the most complete recordings of RT-GNSS displacements to date, helping aid in an initial source characterization over the first few days. In this article, we analyze and make available the archived RT displacement streams and compare their performance to postprocessed results, which we also provide. We find good agreement for all stations showing a noticeable signal. This demonstrates that simple modeling in RT, such as peak ground displacement scaling, would be practically identical to postprocessed results. Similarly, we find good agreement across the full spectral range, from the coseismic offsets $(\sim 0 \mathrm{~Hz})$ to the Nyquist frequency. We also find low latency between the measurement acquisition at the field site and the position calculation at the data center. In aggregate, the performance during the Ridgecrest earthquakes is strong evidence of the viability and usefulness of RT-GNSS as a monitoring tool.
\end{abstract}

\begin{abstract}
Cite this article as Melgar, D.,
T. I. Melbourne, B. W. Crowell, J. Geng, W. Szeliga, C. Scrivner, M. Santillan, and D. E. Goldberg (2019). Real-Time HighRate GNSS Displacements: Performance Demonstration during the 2019 Ridgecrest, California, Earthquakes, Seismol. Res. Lett. XX, 1-9, doi: 10.1785/ 0220190223.
\end{abstract}

\section{Introduction}

Global Navigation Satellite Systems (GNSS) comprise constellations of navigation satellites such as the Global Positioning System (GPS). GNSS satellites broadcast microwave signals that are recorded by land-based antennas and receivers and can be used to obtain the position of the antenna. If the antenna moves, as it would during an earthquake, the position changes can be calculated in real time (RT) to obtain displacement seismograms. GNSS displacement waveforms have accuracy at the centimeter level and so are the most useful as a ground-motion recording instrument during moderate-to-large events and at local-to-regional distances (e.g., Nikolaidis et al., 2001; Larson et al., 2003; Bock et al., 2011). They complement strong-motion recordings because they are a noninertial measurement system and do not suffer from baseline offsets traditionally found in accelerograms (e.g., Boore and Bommer, 2005). Baseline offsets in accelerograms make unambiguous integration to displacement difficult and effectively limit the usefulness of the resulting waveforms, typically to periods shorter than $\sim 10 \mathrm{~s}$ (e.g., Melgar et al., 2013). In contrast, high-rate (HR) GNSS recordings, usually sampled at $1-10 \mathrm{~Hz}$, provide reliable strong-motion displacement measurements down to $0 \mathrm{~Hz}$ (the static offset).
This ability of HR-GNSS displacement recordings to supplement strong-motion accelerations to capture the full complexity of ground motion has long been recognized; reviews of the progress in this regard can be found in Bock and Melgar (2016) and Larson (2019). Databases of postprocessed recordings have been made available for earthquakes in the M 6-9 range (Ruhl et al., 2018). It has been demonstrated that RT GNSS can be used to obtain rapid magnitudes (e.g., Crowell et al., 2013; Melgar et al., 2015) often before rupture is complete. It can also be used to obtain higher-order earthquake source products such as moment tensors (Melgar et al., 2012; O'Toole et al., 2012; Riquelme et al., 2016) and distributed slip (e.g., Crowell et al., 2012; Wright et al., 2012). As a result, RT GNSS is being incorporated into both earthquake and tsunami

\footnotetext{
1. Department of Earth Sciences, University of Oregon, Eugene, Oregon, U.S.A.; 2. Pacific Northwest Geodetic Array, Department of Geological Sciences, Centra Washington University, Ellensburg, Washington, U.S.A.; 3. Department of Earth and Space Sciences, University of Washington, Seattle, Washington, U.S.A.; 4. GNSS

Center, University of Wuhan, Wuhan, China

*Corresponding author: dmelgarm@uoregon.edu

(c) Seismological Society of America
} 
early warning systems (Crowell et al., 2016; Kawamoto et al., 2017; Murray et al., 2018).

However, RT positioning is challenging. Unlike inertial seismic sensors, which directly record ground motion, GNSS relies on measuring the time of flight of the microwave signals from the antenna to the broadcasting satellite to obtain the "pseudorange." Because many satellites are visible at any point in time (typically more than six), the pseudoranges can be combined to solve for the position of the antenna at any point in time. Measurements of the phase with which the microwave signals arrive are further used to refine these solutions to the centimeter level of accuracy. For point positioning, in which a GNSS receiver is positioned within a global reference frame rather than relative to nearby stations that are held fixed (Zumberge et al., 1997), positioning depends on knowledge of variables external to the ground motion produced by the earthquake. Two important factors are (1) a precise knowledge of the satellite clocks, needed to determine when the microwave signal is broadcast by the satellite, and (2) the satellite orbits, necessary to determine the position of the satellites in the sky. Because of myriad factors such as solar wind pressure, relativity, and others, both clocks and orbits drift with time. In postprocessing, "final" clocks and orbits, determined with about two weeks latency by the International GNSS Service (IGS), can be used to convert the raw GNSS phase and range recordings to the displacement waveforms that have now become commonplace. In RT, however, lower accuracy "broadcast" satellite orbits and clocks are insufficiently accurate for point positioning and must therefore be continually updated with corrections derived from continuous regional or global analyses. Thus, the process of positioning any given station in RT entails streaming in both raw satellite observables made at that station as well as a variety of ancillary products derived from separate analyses. All of this makes HR-GNSS positioning more difficult than using an inertial sensor, and potentially degrades the ultimate precision of estimated displacements.

RT positioning has been discussed for almost two decades now (e.g., Nikolaidis et al., 2001), and many countries operate RT-GNSS networks as a result of these efforts. However, most of the RT components of such networks have been circumscribed to telemetering the raw GNSS observables (pseudorange and phase) in RT from the field to a data center. Although a number of RT positioning codes have been described and made available (e.g., Geng et al., 2013, 2019), all of the previous work that discussed the quality and usefulness of GNSS waveforms for RT seismology has used raw data collected in RT, but with positions obtained in a postprocessing mode. Few, if any, reports exist of actual operational performance of RT GNSS during a significant earthquake.

The Geodesy Laboratory at Central Washington University (CWU) has for several years been producing RT positions with a sample rate of $1 \mathrm{~Hz}$ from stations across the West Coast of the United States using CWU's Fastlane positioning system
(Santillan et al., 2013). Fastlane produces position estimates based primarily on GNSS carrier phase observables (currently only from the GPS constellation) and satellite clock corrections provided by the RT Service of the IGS. The GPS carrier phase data are internally continuously calibrated using geometry-free combinations of the L1 and L2 pseudorange and phase observables. This calibration step is a Kalman-filter-based algorithm that simultaneously estimates the best floating point ambiguities while monitoring and correcting for possible cycle slips. Fastlane uses GPS carrier phase based only, unlike other precise point positioning (PPP) algorithms (e.g., Kouba and Héroux, 2001) that rely on both phase and pseudorange. This approach to PPP relies on the fact that the calibration procedure greatly mitigates the influence of code multipath that may affect the estimation of the floating point ambiguities. Using well-calibrated data, Fastlane uses only half the number of input observations, therefore, reducing the overall computation of the position estimates, which also translates into smaller latencies. These low-latency solutions are served to the U.S. Geological Survey for use in the ShakeAlert earthquake early warning system (Murray et al., 2018) and to the National Oceanographic and Atmospheric Administration for a pilot project on tsunami warning (Melbourne et al., 2018). During the 4 July 2019 M 6.4 and 6 July 2019 M 7.1 Ridgecrest, California, earthquakes (Barnhart et al., 2019; Godlberg et al., 2019; Ross et al., 2019; Fig. 1) roughly 700 stations from the Network of the Americas (NOTA) operated by UNAVCO, Inc., were being positioned in RT with Fastlane by CWU. Fastlane employs carrier phase-only-based positioning rather than pseudorange because phase alone is far less contaminated by multipath error, one of the largest sources of noise in HR positioning. Fastlane depends on a highly efficient algorithm for the resolution of carrier phase initial ambiguities, which for most stations can be initially resolved in 20-30 s. Here, we will compare these truly end-to-end RT positions against solutions obtained after the earthquakes with final clocks and orbits. We will show that, although compared with the final solutions RT positions are noisier, they are reliable enough to be useful for RT characterization of the earthquakes.

\section{Observational Setting: GNSS Recordings}

Figure 1 shows the NOTA permanent GNSS stations that recorded the Ridgecrest sequence. Of these, a subset of nine was being positioned in RT by CWU during the earthquake and had displacement signals larger than the background noise. We focus our analysis on this subset, which includes recordings of both earthquakes.

To assess the quality of the RT displacement solutions, we compare them against postprocessed $1 \mathrm{~Hz}$ solutions obtained using the PPP code described by Geng et al. (2019). We used the rapid satellite orbit, phase clock, and phase bias products generated by Wuhan University with a latency of $24 \mathrm{hr}$ to 
口 M 6.4 RT-GNSS

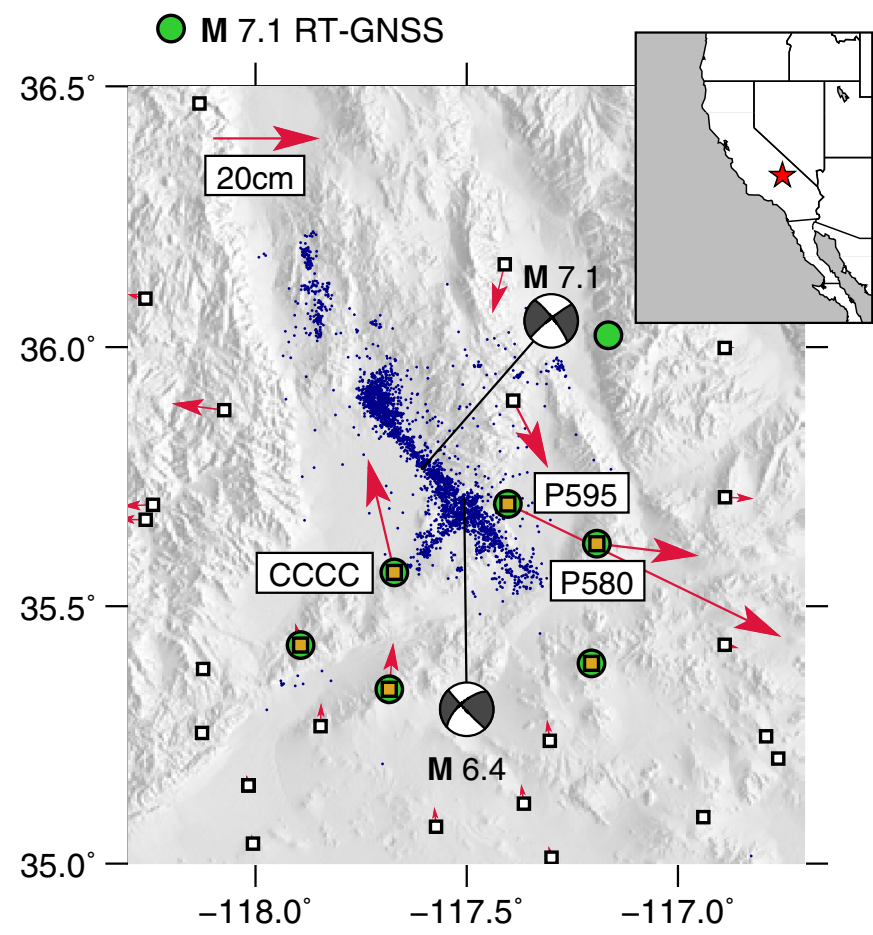

Figure 1. Real-time (RT) stations analyzed in this study. White squares denote the Network of the Americas permanent sites. Orange squares are stations for which RT-Global Navigation Satellite Systems (GNSS) data exist for the M 6.4 earthquake. Green circles are stations for which RT-GNSS data exist for the M 7.1 earthquake. Small blue dots are aftershocks from the first two weeks after the 4 July $\mathbf{M} 6.4$ earthquake from the Southern California Earthquake Center Caltech (SCEDC) catalog (SCEDC, 2013). Arrows are coseismic offsets for the $\mathbf{M} 7.1$ earthquake from the Geodetic Facility for the Advancement of Geoscience (GAGE) solution (Herring et al., 2016). Inset shows the location of the study. The star is the $\mathbf{M} 7.1$ hypocenter. The color version of this figure is available only in the electronic edition.
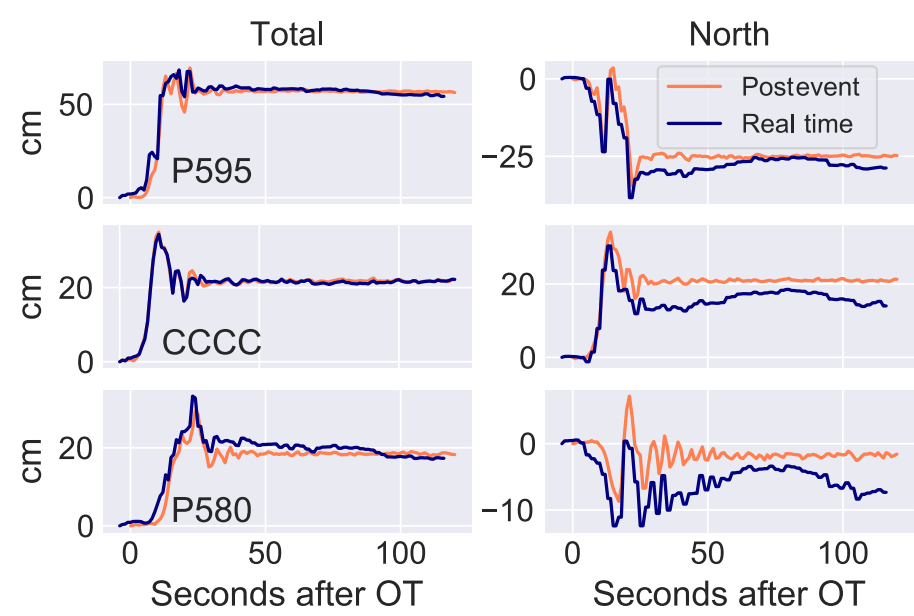

Figure 2. Examples of GNSS waveforms for the $\mathbf{M} 7.1$ earthquake. Station locations are in Figure 1. OT, origin time. The enable postprocessed PPP solutions with integer ambiguities resolved. The latest IGS antenna phase center model, code bias model and International Earth Rotation and Reference Systems Service solid Earth tide, ocean tidal displacement, and pole tide models were applied. We also used global mapping functions to project zenith tropospheric delays onto slant directions with standard meteorological parameters. Examples of the two sets of $1 \mathrm{~Hz}$ waveforms, postprocessed and RT, can be seen in Figure 2. There are evident differences between them; the RT solutions are noisier. A detailed discussion and analysis of these differences will follow. Here, we are also interested in examining any impacts that the sample rate might have. Because the NOTA data are also recorded at $5 \mathrm{~Hz}$, for each of the analyzed stations we produced higher rate $5 \mathrm{~Hz}$ sampled positions as well. The $1 \mathrm{~Hz} \mathrm{RT}$ and 1 and $5 \mathrm{~Hz}$ postprocessed data are made available in miniSEED format (see Data and Resources).

Finally, we study the impact of the higher noise RT solutions on the features of the displacement waveforms typically used for warning and hazards applications, namely the peak ground displacement (PGD) and the coseismic or static offsets. For PGD, we can compare directly between RT and postprocessed solutions. For the coseismic offsets, we rely on postevent offset estimations from the UNAVCO Geodetic Facility for the Advancement of Geoscience (GAGE) Facility for both M 6.4 and $\mathbf{M} 7.1$ events (Herring et al., 2016). The offsets from the M 7.1 earthquake are shown in Figure 1.

\section{Data Quality}

As shown in Figure 2, there are obvious differences between $\mathrm{RT}$ and postprocessed data. When the signals are small, as in the vertical components, the differences are easier to spot. This increased noise level in the RT solutions impacts the frequency-domain performance as well. Figure 3 shows an example of the amplitude spectrum for the three components of displacement at station P595 during the M 7.1 earthquake.
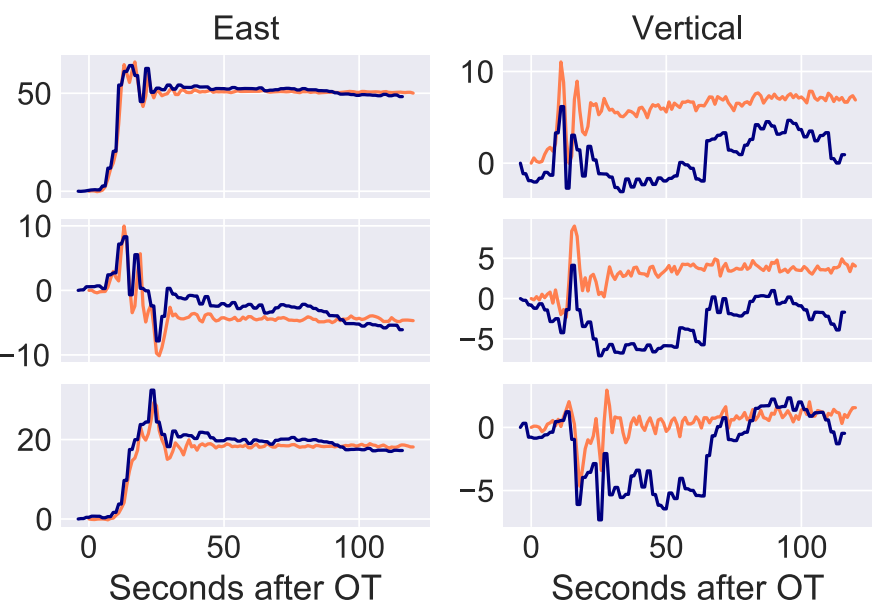

color version of this figure is available only in the electronic edition. 


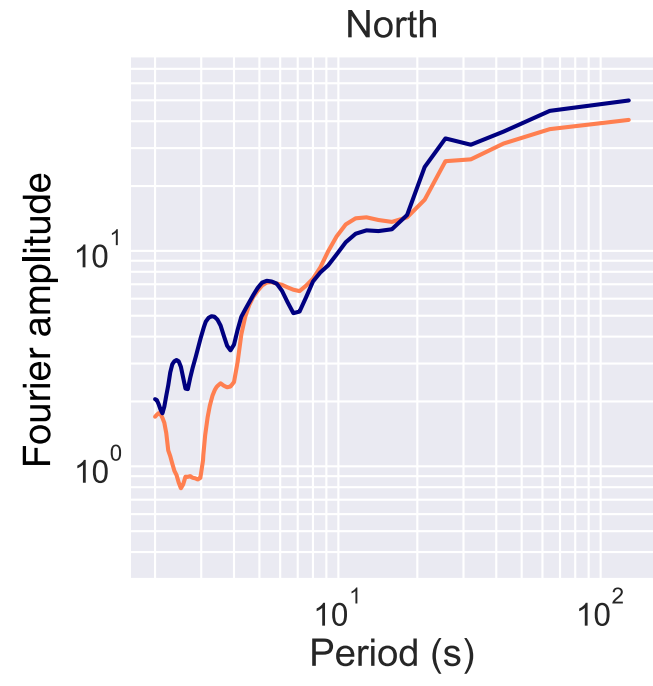

This was calculated using the multitaper method of Prieto et al. (2009). The overall spectra have similar shapes, but there are differences across all frequencies. To understand if there is a systematic pattern to this, we calculate the individual spectral biases $b_{i k}$ at a station $i$ and at frequency $f_{k}$ as

$b_{j k}=\ln \frac{A_{P}^{i}\left(f_{k}\right)}{A_{\mathrm{RT}}^{i}\left(f_{k}\right)}$,

in which ln is the natural logarithm, $A_{\mathrm{RT}}^{i}\left(f_{k}\right)$ is the RT amplitude spectrum at station $i$ and frequency $f_{k}$, and $A_{P}^{i}\left(f_{k}\right)$ is the amplitude spectrum for the postprocessed waveform. Then, for all the stations that recorded both the $\mathbf{M} 6.4$ and $\mathbf{M} 7.1$ earthquakes, we calculate the total spectral bias as

$B\left(f_{k}\right)=\sum_{I=1}^{n} b_{i k}$,

in which $n$ is the total number of waveforms. The results are shown in Figure 4. Positive values indicate that the spectral content at a particular frequency is larger in the postprocessed data, negative biases that the spectral content is larger in the RT waveforms. A value close to zero indicates that the spectral content is similar. The results show a "sweet-spot" for these waveforms between $\sim 4$ and $30 \mathrm{~s}$ when the frequency content is very similar. This is consistent with the periods at which one would expect significant radiation (e.g., Beresnev and Atkinson, 1997), given the expected source duration for $\mathbf{M} 6.4$ and $\mathbf{M} 7.1$ earthquakes. At periods shorter and longer than that, $B$ is consistently negative indicating that the noise in the RT time series introduces a consistent spectral bias.

Given these differences between RT and postprocessed data, it is important to quantify the impacts to the two most common features of the displacement waveforms used for early warning and hazards, the PGD and the coseismic offsets. Figure 5 shows the difference between the RT and postprocessed PGD values. They all fall close to the 1:1 line, and the standard deviation of the difference between them is $6.5 \mathrm{~cm}$. Assuming that the
East

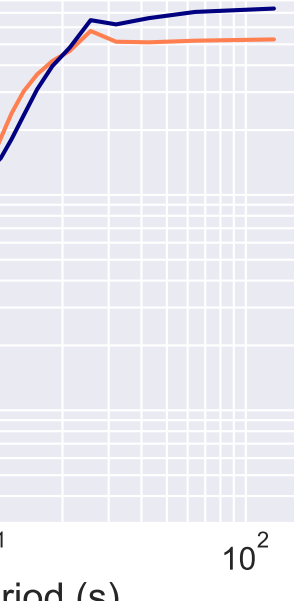

Period (s)

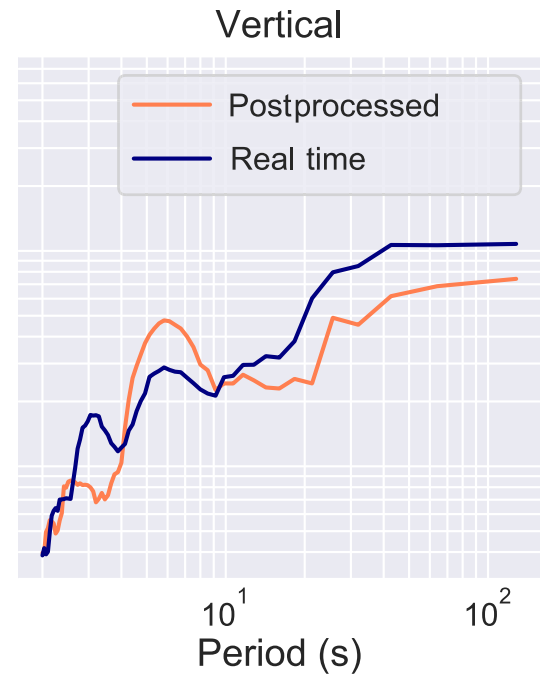

Figure 3. Multitaper estimates of the amplitude spectra for station P595 during the $\mathbf{M} 7.1$ earthquake. The color version of this figure is available only in the electronic edition.

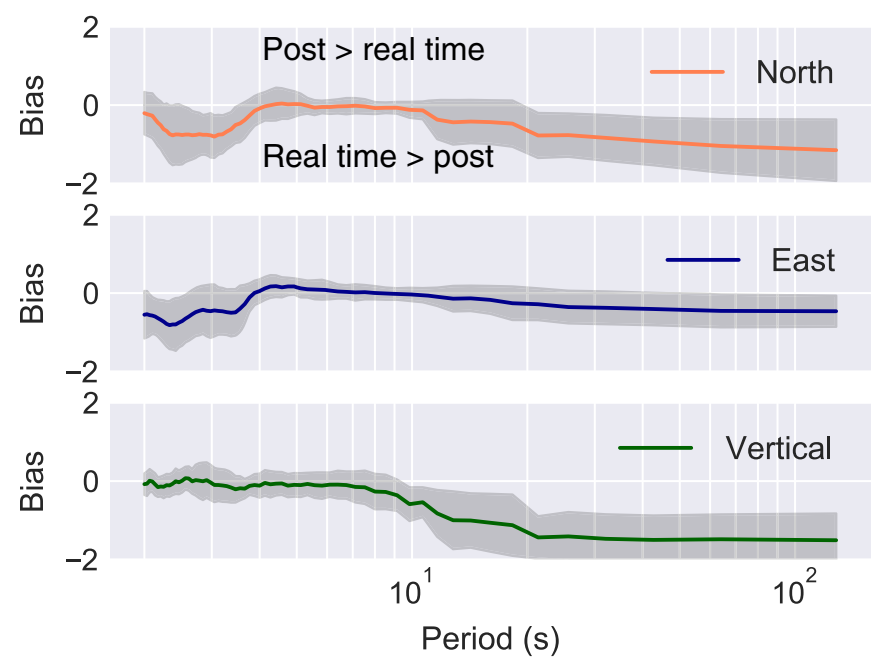

Figure 4. Amplitude spectra bias in nondimensional units between RT and postprocessed data. The biases are calculated over all stations and for both earthquakes. The shaded region indicates one standard deviation. The color version of this figure is available only in the electronic edition.

postprocessed value is the ground truth, then this standard deviation is an empirical estimate of the RT uncertainty in PGD. If we consider a three-component PGD, there is one significant outlier. If the PGD is calculated only on the horizontal component (Fig. 5b) then the standard deviation improves to $4.1 \mathrm{~cm}$. As noted previously by Melgar et al. (2015) for moderate $(\mathbf{M} \sim 7)$ magnitude events for which GNSS noise is close to the size of the observed signals, considering only the horizontal PGD can lead to more robust measurements. This is supported by what is seen for the Ridgecrest earthquakes. This is not surprising because the vertical component is on average five times 

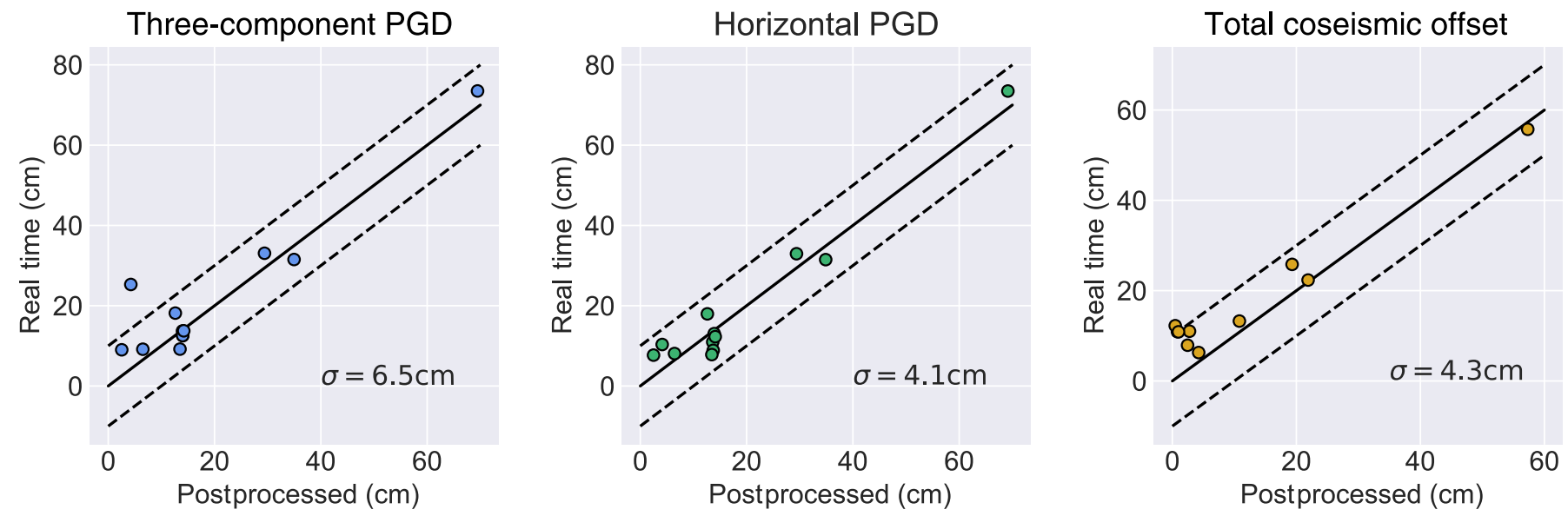

noisier than the horizontal components (Bock et al., 2011), and the noise level of the positions does not increase appreciably with more displacement. Wang et al. (2012) found a small increase in the noise level of GNSS positions under high levels of shaking, but when considering the signal-to-noise ratio of the positions, this effect is negligible

We also measure the coseismic offsets on the RT waveforms using the moving-average method used by Crowell et al. (2016) employing an $S$-wave travel-time mask of $2 \mathrm{~km} / \mathrm{s}$. When compared to the postprocessed offsets (Fig. 5c), we measured a standard deviation of $4.3 \mathrm{~cm}$ in the difference between them. We also see a slight positive bias toward RT offsets being larger than the postprocessed ones. This is likely due to the longperiod noise identified in Figure 3.

\section{Initial Assessment of Impacts ON RT Performance}

Is this performance good enough for RT seismology and rapid response? Paramount to geodetic early warning systems is the ability to properly ascertain the PGDs and coseismic offsets in a timely manner. Given the $4-6 \mathrm{~cm}$ uncertainty in PGD (Fig. 5), we can quantify its impact in RT magnitude calculations. The original PGD scaling law proposed by Crowell et al. (2013) describes the magnitude of an earthquake (M) with respect to the three-component PGD and the distance to the source $(R)$ such that

$$
\log (\mathrm{PGD})=A+B \times \mathbf{M}+C \times \mathbf{M} \times \log (R),
$$

in which $\log$ is the base $10 \operatorname{logarithm}$, whereas $A, B$, and $C$ are coefficients derived through a linear regression using past earthquakes. These coefficients have been updated several times (e.g., Melgar et al., 2015; Crowell et al., 2016; Ruhl et al., 2018), but they are fairly consistent and lead to minimal differences in magnitude estimation. For the Ridgecrest earthquakes, we found a standard deviation of $6.5 \mathrm{~cm}$ for the threecomponent PGD values between the RT and postprocessed values. Using the log-summation rule, we can represent the uncertainty in the relationship as
Figure 5. Comparison between RT and postprocessed peak ground displacement (PGD) and coseismic offsets. The thick line indicates the 1:1 correspondence. Dashed lines indicate $\pm 10 \mathrm{~cm}$ from this value. The color version of this figure is available only in the electronic edition.

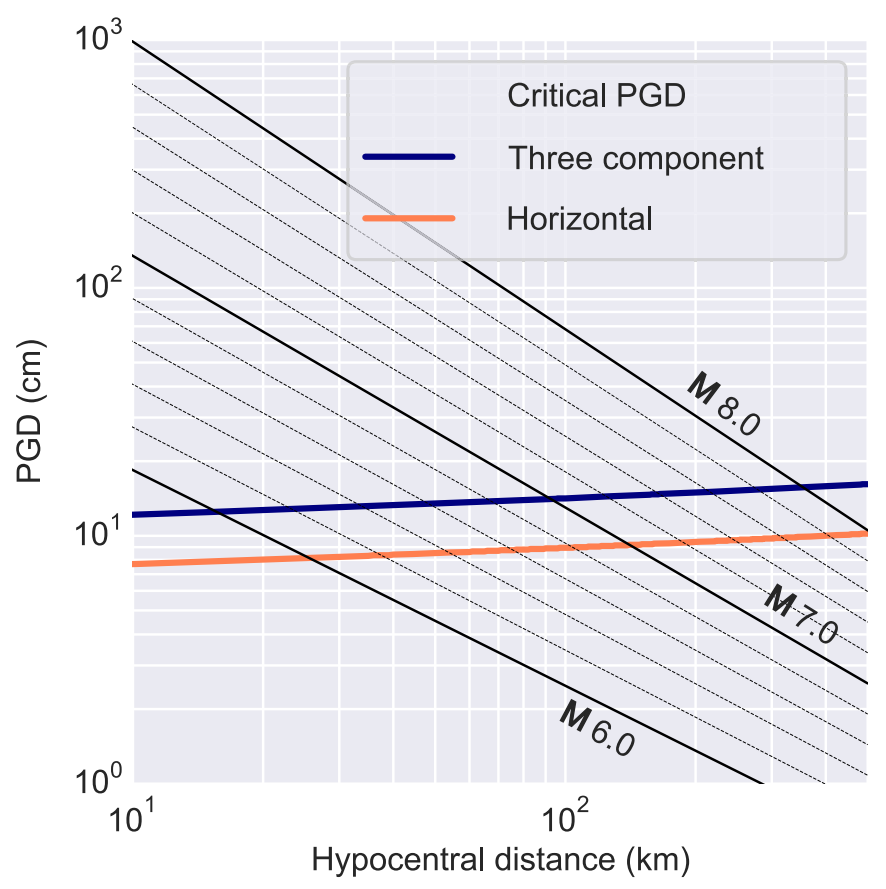

Figure 6. Critical PGD value based on the three-component and horizontal-only values of the PGD uncertainties. The expected PGD amplitude as a function of earthquake magnitude and hypocentral distance are also shown. The color version of this figure is available only in the electronic edition.

$$
\begin{aligned}
\log \left(\mathrm{PGD} \pm \sigma_{\mathrm{PGD}}\right) & =\log (\mathrm{PGD})+\log \left(1 \pm \frac{\mathrm{PGD}}{\sigma_{\mathrm{PGD}}}\right) \\
& =A+B \times \mathbf{M}+C \times \mathbf{M} \times \log (R) .
\end{aligned}
$$

Using the most recent regression coefficients from Ruhl et al. (2018), we solve for the PGD value required at certain distances 

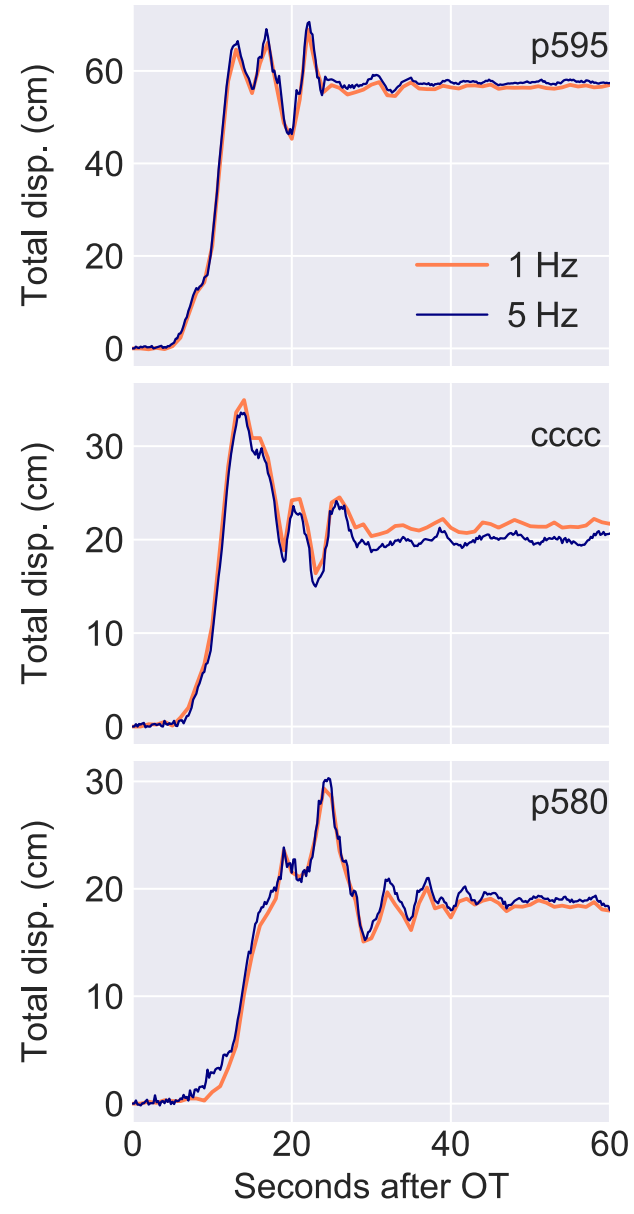

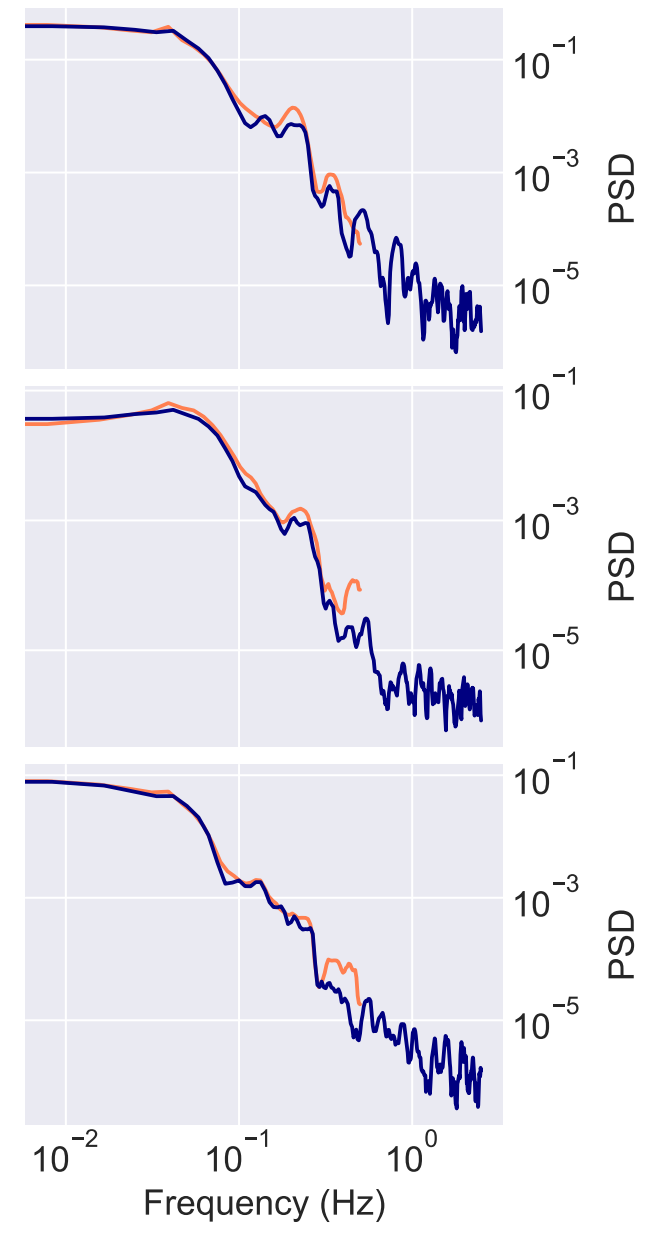

Figure 7. Comparison between 5 and $1 \mathrm{~Hz}$ waveforms and spectra for the total displacements of the stations in Figure 2. PSD, power spectral density. The color version of this figure is available only in the electronic edition. to keep the total magnitude estimate variability below \pm 0.3 magnitude units given the $6.5 \mathrm{~cm} \sigma_{\mathrm{PGD}}$ value. We term this the "critical PGD"; this is the value to which PGD must rise in order for us to be confident that the magnitude estimation is within the specified tolerance of \pm 0.3 magnitude units. The results are shown in Figure 6, we find that at a distance of $100 \mathrm{~km}$, for example, the PGD value needs to be greater than $14 \mathrm{~cm}$ using the three-component PGD or $9 \mathrm{~cm}$ using only horizontal components $\left(\sigma_{\mathrm{PGD}}=4.1 \mathrm{~cm}\right)$. Plotted in Figure 6 as well are the expected values of PGD for different magnitude earthquakes using the coefficients of Ruhl et al. (2018). We can see that for an $\mathbf{M} 6$ earthquake, for example, stations need to be within $\sim 25 \mathrm{~km}$ of the source to exceed the critical PGD value. For an earthquake of $\mathbf{M} 7$, stations must be within $150 \mathrm{~km}$, and for an $\mathbf{M} 8$ earthquake, within $500 \mathrm{~km}$. This empirical determination of the PGD uncertainty and the critical PGD value are a useful guide to determine the effectiveness of GNSS for different size earthquakes and at certain distances from the earthquake source. For the Ridgecrest earthquake, two-thirds motions (e.g., Smalley, 2009), and that $10 \mathrm{~Hz}$ would be a better sampling rate for high-fidelity displacements.

We do not find evidence of error introduced by the sampling rate. Figure 7 shows the 1 and $5 \mathrm{~Hz}$ total displacement waveforms and amplitude spectra for the same three sites as Figure 2. Although there is perhaps some suggestion of aliasing from the slightly elevated spectral content between 2 and $3 \mathrm{~s}$ period in the $1 \mathrm{~Hz}$ waveforms, overall the spectra are very similar to each other. In addition, the difference in the PGD values between 1 and $5 \mathrm{~Hz}$ is quite small (Fig. 8) with a standard deviation of only $0.83 \mathrm{~cm}$.

In aggregate, this shows that both of the important features of GNSS waveforms, which are used for rapid source modeling, PGD, and coseismic offsets, are of sufficient quality in RT products as to be useful for warning applications. Indeed, the latency of the positions (Fig. 9) measured from the field site to the position estimate being complete is of only $\sim 1-2 \mathrm{~s}$ across all the RT sites shown in Figure 1. This latency includes the time of arrival of a position estimate minus the timestamp of 


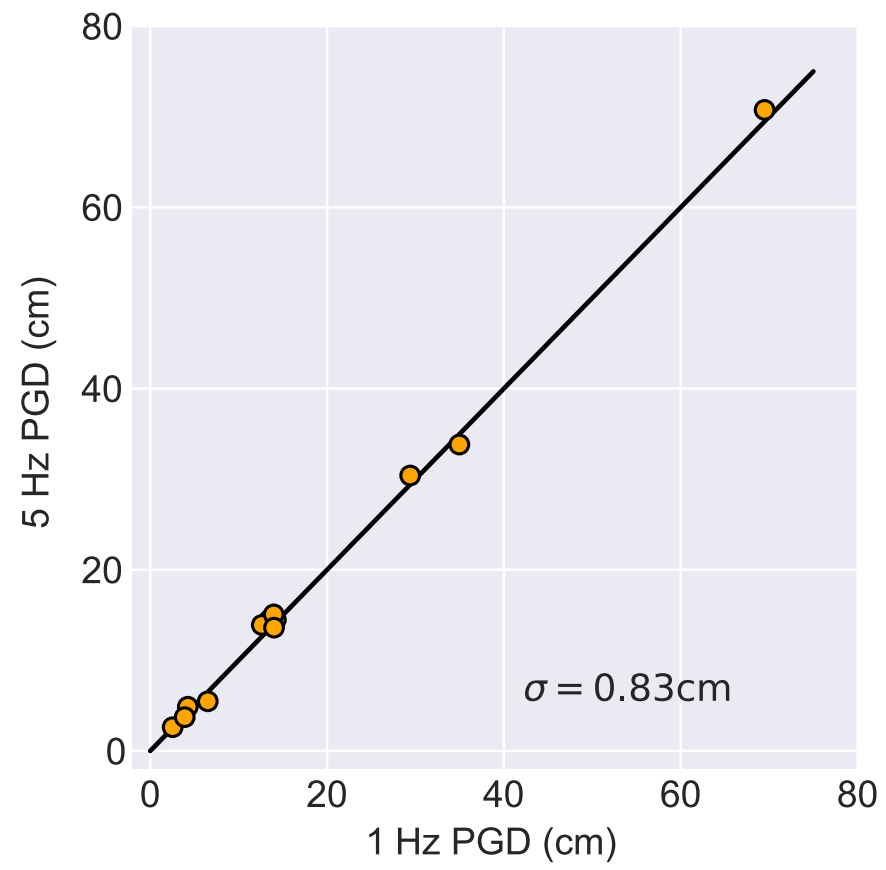

Figure 8. Difference between the PGD values measured on the $1 \mathrm{~Hz}$ versus $5 \mathrm{~Hz}$ waveforms. The line indicates the 1:1 correspondence. The color version of this figure is available only in the electronic edition.

the epoch itself and includes both data telemetry and processing time. For a $1 \mathrm{hr}$ period bracketing the $\mathbf{M} 7.1$ earthquake, the latency averaged $1.4 \mathrm{~s}$ for all stations that show resolvable coseismic offsets (Fig. 9). For NOTA sites, the telemetry path is from the field site to UNAVCO in Boulder, Colorado, and then to CWU. This extra hop introduces $\sim 250 \mathrm{~ms}$ of delay. There is a further $\sim 1 \mathrm{~s}$ delay from packetization and multiplexing of the data to bundle all the configured sites and send them to the output socket. With PGD estimates available within $15 \mathrm{~s}$ of the origin time for the sites closest to the source of the $\mathbf{M} 7.1$ earthquake (Fig. 2), it would have been possible for GNSS to contribute in a meaningful way to the ShakeAlert Earthquake Early Warning system during these earthquakes. Coseismic offset estimates are made soon thereafter, and thus by $\sim 20 \mathrm{~s}$ after the origin time (including telemetry delays) a complete preliminary characterization of the earthquake, which includes the moment tensor and a slip inversion, would be possible.

\section{Summary}

Although RT GNSS has been studied before, and many researchers have argued that it should play a prominent role in RT seismological systems, the 2019 Ridgecrest, California, earthquakes are the first opportunity we have had to truly assess the end-to-end performance of an already operational RT-GNSS positioning system designed and built to monitor earthquakes. Here, we find that during the events the NOTA stations operated by UNAVCO delivered data robustly and

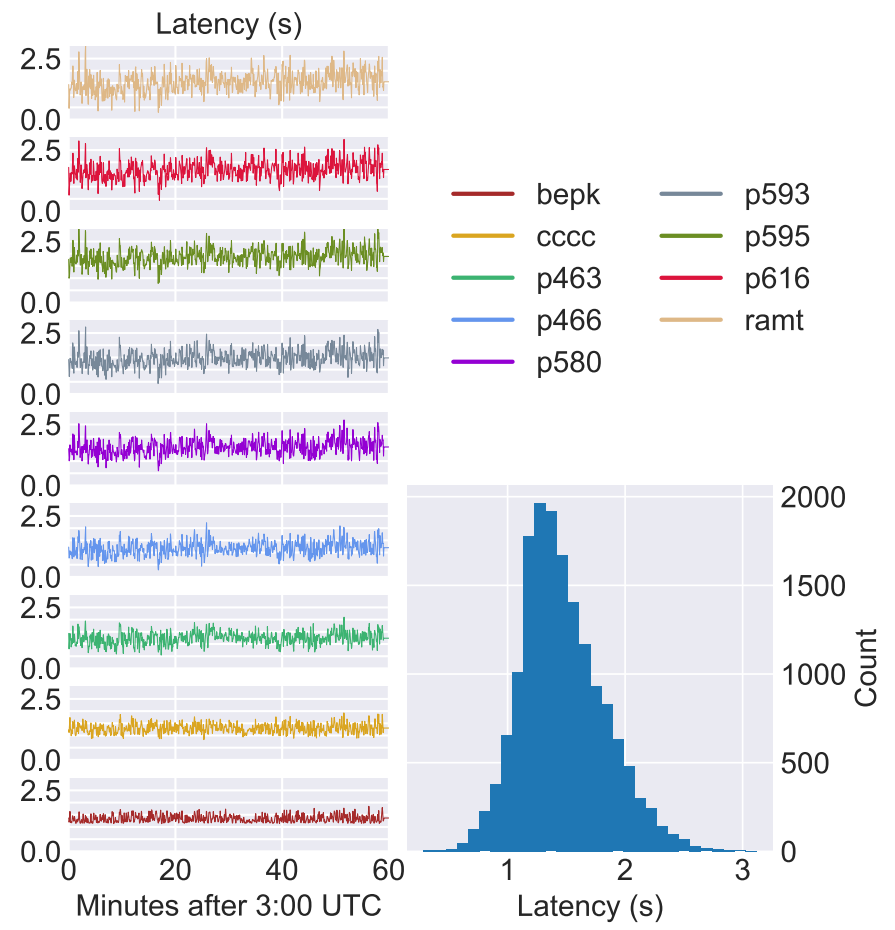

Figure 9. Positioning latency by station during a $1 \mathrm{hr}$ period bracketing the $\mathbf{M} 7.1$ earthquake. Latency is defined as the time of arrival of the estimated position for a given epoch into a position database minus the timestamp of the observables themselves, and includes acquisition, telemetery, and processing time. The color version of this figure is available only in the electronic edition.

with low latency. We also find that the FastLane positioning service operated at CWU produced displacement solutions of good quality when compared to postprocessed waveforms. An analysis of the quality of the PGD and coseismic offsets determined from the RT data clearly shows that for moderate-to-large events GNSS performs well and provides useful and valuable data that can supplement traditional RT seismological algorithms. Overall, the events were an important realworld test of RT-GNSS structures for which, we argue, the system performed as expected.

\section{Data and Resources}

Real-time $1 \mathrm{~Hz}$ and postprocessed 1 and $5 \mathrm{~Hz}$ three-component displacement waveforms are provided in miniSEED format and archived at Zenodo (https://zenodo.org/record/3366342). Static offsets from the Geodetic Facility for the Advancement of Geoscience (GAGE) solution can be obtained from the UNAVCO community response page available at https://www.unavco.org/highlights/2019/ridgecrest.html. RINEX files with the raw Global Navigation Satellite Systems (GNSS) data can be obtained from the UNAVCO high-rate ftp archive (ftp:// data-out.unavco.org/pub/highrate/). The postprocessing of the GNSS waveforms was performed with the PRIDE precise point positioning (PPP) ambiguity resolution code available at https://www.ngs.noaa. gov/gps-toolbox/PRIDE.htm. All websites were last accessed June 2019. 


\section{Acknowledgments}

This work was partially funded by National Aeronautics and Space Administration (NASA) Grant Numbers NNXIOAD15G and 80NSSC19K0359 and the U.S. Geological Survey National Earthquake Hazards Reduction Program (USGS-NEHRP) Grant Number G17AC00344 to Central Washington University, and RRNES18-0001 and DISASTER18-0040 to University of Oregon. Data are from Network of the Americas (NOTA) stations, funded by the National Science Foundation (NSF) and operated by UNAVCO, Inc. Data based on services provided by the Geodetic Facility for the Advancement of Geoscience (GAGE) Facility, operated by UNAVCO, Inc., with support from the NSF and NASA under NSF Cooperative Agreement Number EAR-1724794.

\section{References}

Barnhart, W. D., G. P. Hayes, and R. D. Gold (2019). The July 2019 Ridgecrest, California earthquake sequence: Kinematics of slip and stressing in cross-fault ruptures, Geophys. Res. Lett. 46, doi: 10.1029/2019GL084741.

Beresnev, I. A., and G. M. Atkinson (1997). Modeling finite-fault radiation from the wn spectrum, Bull. Seismol. Soc. Am. 87, no. 1, 67-84.

Bock, Y., and D. Melgar (2016). Physical applications of GPS geodesy: A review, Rep. Progr. Phys. 79, no. 10, 106801.

Bock, Y., D. Melgar, and B. W. Crowell (2011). Real-time strongmotion broadband displacements from collocated GPS and accelerometers, Bull. Seismol. Soc. Am. 101, no. 6, 2904-2925.

Boore, D. M., and J. J. Bommer (2005). Processing of strong-motion accelerograms: Needs, options and consequences, Soil Dynam. Earthq. Eng. 25, no. 2, 93-115.

Crowell, B. W., Y. Bock, and D. Melgar (2012). Real-time inversion of GPS data for finite fault modeling and rapid hazard assessment, Geophys. Res. Lett. 39, no. 9, doi: 10.1029/2012GL051318.

Crowell, B. W., D. Melgar, Y. Bock, J. S. Haase, and J. Geng (2013). Earthquake magnitude scaling using seismogeodetic data, Geophys. Res. Lett. 40, no. 23, 6089-6094.

Crowell, B. W., D. A. Schmidt, P. Bodin, J. E. Vidale, J. Gomberg, J. Renate Hartog, V. C. Kress, T. I. Melbourne, M. Santillan, S. E. Minson, et al. (2016). Demonstration of the Cascadia G-FAST geodetic earthquake early warning system for the Nisqually, Washington, earthquake, Seismol. Res. Lett. 87, no. 4, 930-943.

Geng, J., Y. Bock, D. Melgar, B. W. Crowell, and J. S. Haase (2013). A new seismogeodetic approach applied to GPS and accelerometer observations of the 2012 Brawley seismic swarm: Implications for earthquake early warning, Geochem. Geophys. Geosys. 14, no. 7, 2124-2142.

Geng, J., X. Chen, Y. Pan, S. Mao, C. Li, J. Zhou, and K. Zhang (2019). PRIDE PPP-AR: An open-source software for GPS PPP ambiguity resolution, GPS Solutions 23, no. 4, 91.

Goldberg, D. E., D. Melgar, A. Thomas, V. J. Sahakian, X. Xu, J. Geng, and B. W. Crowell (2019). Complex rupture of an immature fault zone: A simultaneous kinematic model of the 2019 Ridgecrest, CA earthquakes, EarthArXiv doi: 10.31223/osf.io/s79bk.

Herring, T. A., T. I. Melbourne, M. H. Murray, M. A. Floyd, W. M. Szeliga, R. W. King, D. A. Phillips, C. M. Puskas, M. Santillan, and L. Wang (2016). Plate Boundary Observatory and related networks: GPS data analysis methods and geodetic products, Rev. Geophys. 54, no. 4, 759-808.
Kawamoto, S., Y. Ohta, Y. Hiyama, M. Todoriki, T. Nishimura, T. Furuya, Y. Sato, T. Yahagi, and K. Miyagawa (2017). REGARD: A new GNSS-based real-time finite fault modeling system for GEONET, J. Geophys. Res. 122, no. 2, 1324-1349.

Kouba, J., and P. Héroux (2001). Precise point positioning using IGS orbit and clock products, GPS Solutions 5, no. 2, 12-28.

Larson, K. M. (2019). Unanticipated uses of the Global Positioning System, Ann. Rev. Earth Planet. Sci. 47, 19-40.

Larson, K. M., P. Bodin, and J. Gomberg (2003). Using 1-Hz GPS data to measure deformations caused by the Denali fault earthquake, Science 300, no. 5624, 1421-1424.

Melbourne, T. I., T. Stough, Y. Bar-Sever, Y. Bock, and T. Song (2018). Operationalizing GNSS as a fourth observation for local tsunami warning, presented at the 2018 Fall Meeting, AGU, Washington, D.C., 10-14 December, Abstract NH34B-02.

Melgar, D., Y. Bock, and B. W. Crowell (2012). Real-time centroid moment tensor determination for large earthquakes from local and regional displacement records, Geophys. J. Int. 188, no. 2, 703-718.

Melgar, D., Y. Bock, D. Sanchez, and B. W. Crowell (2013). On robust and reliable automated baseline corrections for strong motion seismology, J. Geophys. Res. 118, no. 3, 1177-1187.

Melgar, D., B. W. Crowell, J. Geng, R. M. Allen, Y. Bock, S. Riquelme, E. M. Hill, M. Protti, and A. Ganas (2015). Earthquake magnitude calculation without saturation from the scaling of peak ground displacement, Geophys. Res. Lett. 42, no. 13, 5197-5205.

Murray, J. R., B. W. Crowell, R. Grapenthin, K. Hodgkinson, J. O. Langbein, T. Melbourne, D. Melgar, S. E. Minson, and D. A. Schmidt (2018). Development of a geodetic component for the US West Coast earthquake early warning system, Seismol. Res. Lett. 89, no. 6, 2322-2336.

Nikolaidis, R. M., Y. Bock, P. J. de Jonge, P. Shearer, D. C. Agnew, and M. Van Domselaar (2001). Seismic wave observations with the Global Positioning System, J. Geophys. Res. 106, no. B10, 21,897-21,916.

O'Toole, T. B., A. P. Valentine, and J. H. Woodhouse (2012). Centroid-moment tensor inversions using high-rate GPS waveforms, Geophys. J. Int. 191, no. 1, 257-270.

Prieto, G. A., R. L. Parker, and F. L. Vernon III (2009). A Fortran 90 library for multitaper spectrum analysis, Comput. Geosci. 35, no. 8, 1701-1710.

Riquelme, S., F. Bravo, D. Melgar, R. Benavente, J. Geng, S. Barrientos, and J. Campos (2016). W phase source inversion using high-rate regional GPS data for large earthquakes, Geophys. Res. Lett. 43, no. 7, 3178-3185.

Ross, Z. E., B. Idini, Z. Jia, O. L. Stephenson, M. Zhong, X. Wang, Z. Zhan, M. Simons, E. J. Fielding, S. H. Yun, E. Hauksson, et al. (2019). Hierarchical interlocked orthogonal faulting in the 2019 Ridgecrest earthquake sequence, Science 366, no. 6463, 346-351.

Ruhl, C. J., D. Melgar, J. Geng, D. E. Goldberg, B. W. Crowell, R. M. Allen, Y. Bock, S. Barrientos, S. Riquelme, J. C. Baez, et al. (2018). A global database of strong-motion displacement GNSS recordings and an example application to PGD scaling, Seismol. Res. Lett. 90, no. 1, 271-279.

Santillan, M., T. Melbourne, W. Szeliga, and V. Scrivner (2013). A fast-convergence stream editor for real-time precise point positioning, Annual Meeting of the American Geophysical Union, San Francisco, California, Abstract G53B-0930. 
Smalley, R., Jr. (2009). High-rate GPS: How high do we need to go? Seismol. Res. Lett. 80, no. 6, 1054-1061.

Southern California Earthquake Center Caltech (SCEDC) (2013). Southern California Earthquake Center Caltech, Dataset, doi: 10.7909/C3WD3xH1.

Wang, G., F. Blume, C. Meertens, P. Ibanez, and M. Schulze (2012). Performance of high-rate kinematic GPS during strong shaking: Observations from shake table tests and the 2010 Chile earthquake, J. Geod. Sci. 2, no. 1, 15-30, doi: 10.2478/v10156-011-0020-0.

Wright, T. J., N. Houlié, M. Hildyard, and T. Iwabuchi (2012). Realtime, reliable magnitudes for large earthquakes from $1 \mathrm{~Hz}$ GPS precise point positioning: The 2011 Tohoku-Oki (Japan) earthquake, Geophys. Res. Lett. 39, no. 12, doi: 10.1029/2012GL051894. Zumberge, J. F., M. B. Heflin, D. C. Jefferson, M. M. Watkins, and F. H. Webb (1997). Precise point positioning for the efficient and robust analysis of GPS data from large networks, J. Geophys. Res. 102, no. B3, 5005-5017. 